\title{
A comparative study of manual vaccum aspiration (MVA) \& electric vaccum aspiration (EVA) for pregnancy termination of upto 10 weeks gestation
}

\section{Sudha Biradar Kerure ${ }^{1, *}$, Rajshekhar D. Kerure², Sheela S. Sagarad ${ }^{3}$, Virupakshappa Biradar $^{4}$}

\author{
${ }^{1}$ Associate Professor in OB/GYN, Navodaya Medical College, Raichur, India \\ ${ }^{2}$ Post-Doctoral Trainee in Nephrology, I.P.G.M.E.R. \& S.S.K.M. Hospital, Kolkata, India \\ ${ }^{3}$ Senior Obstetrician \& Gynaecologist, Raichur, India \\ ${ }^{4}$ Professor of Surgery, Navodaya Medical College, Raichur, India
}

Received: 24 March 2013

Accepted: 19 April 2013

*Correspondence:

Dr. Sudha Biradar Kerure,

E-mail: dr_sudhabiradar@rediffmail.com

(C) 2013 Kerure SB et al. This is an open-access article distributed under the terms of the Creative Commons Attribution License, which permits unrestricted use, distribution, and reproduction in any medium, provided the original work is properly cited.

\begin{abstract}
Background: Induced abortion in first trimester is one of the commonly performed operations in obstetrics. Unsafe abortions kill about 70,000 women annually. So, methods of early pregnancy termination commonly used like, Manual Vaccum Aspiration (MVA) \& Electric Vaccum Aspiration (EVA) are compared in this study. The objective was to compare the safety and efficacy of MVA and EVA in early pregnancy termination.

Methods: Two hundred pregnant women of gestation upto 10 weeks wanting first trimester pregnancy termination were subjected to either MVA or EVA. Age of the patient, gravidity, period of gestation, time taken for the procedure, blood loss, complications and duration of hospital stay were studied.

Results: $37 \%$ patients in MVA had grade I pain and 54\% patients in EVA had grade IV pain. $72 \%$ cases in MVA had grade I bleeding \& $48 \%$ in EVA had grade II bleeding. The bleeding after MVA procedure was less as compared to EVA. Common complications noted were incomplete abortion (1\% in MVA \& $4 \%$ in EVA), and cervical laceration (none in MVA and 3\% in EVA). Cervical laceration was common in EVA during insertion of rigid metallic cannula. In MVA, mean average time taken is less by 5-6 minutes and average blood loss is also less by $8 \mathrm{ml}$ as compared to EVA. Women were discharged in 6-8 hours and 12-16 hours in MVA \& EVA respectively.

Conclusions: Women undergoing MVA had overall satisfaction with relation to pain, blood loss, \& duration of hospital stay. MVA had $99 \%$ success rate. So, MVA is safe and effective in abortions upto 10weeks gestation with less complication than EVA.
\end{abstract}

Keywords: Manual vaccum aspiration, Electric vaccum aspiration, First trimester pregnancy termination

\section{INTRODUCTION}

Unwanted pregnancy is a proxy indicator for the unmet need for contraception. In India, women try a variety of remedies to deal with unwanted pregnancies including tablets, decoctions, sticks and visits to unsafe providers. World wide, nearly 40 million abortions take place annually, of which approximately 10-22 million are illegal abortions. ${ }^{1}$ Surgical methods of abortion in first trimester carry several risks like haemorrhage, uterine perforation, incomplete abortion and cervical injury. ${ }^{2}$

Induced abortion is one of the most frequently performed operations in Obstetrics, and one of the most thoroughly studied. Because of a variety of medical and social factors, abortions are most frequently provided in outpatient settings. ${ }^{3}$ 
The overall risk of death from legal abortion is less than 1 per 1,00,000. Illegally induced abortion is a major cause of death among women of reproductive age group. ${ }^{1}$

Almost all the deaths and complications from unsafe abortions are preventable. In developing countries, there is poor utilization of recognized facilities and an unmet need for an easily available method of early pregnancy termination which is both safe and effective. ${ }^{1}$

Technologic advances like, highly sensitive urinary pregnancy tests and transvaginal USG, have allowed early surgical abortion to emerge today as a safe and effective alternative to and back up for medical abortion. ${ }^{4}$

Vaccum aspiration, the method used for $>97 \%$ of pregnancy terminations is a safe and effective means of accomplishing abortion during the first few weeks of gestation. ${ }^{4}$

So, the present study aims at comparing the safety and efficacy of two vaccum aspiration methods - Manual Vaccum Aspiration (MVA) and Electric Vacuum Aspiration (EVA) used for pregnancy termination upto 10 weeks gestation.

\section{METHODS}

This is a prospective randomized comparative study undertaken in 200 patients seeking MTP, in the reproductive age group with a history of less than or equal to 10 weeks gestation, attending Obstetric and Gynaecology OPD of Navodaya Medical College Hospital from January 2010 to December 2012. Institutional Ethical committee approval was taken to undertake this study.

\section{Inclusion Criteria}

Women with history of $\leq 10$ weeks gestation, irrespective of parity, threatened abortions, missed abortions, incomplete abortions, and failed medical abortions.

\section{Exclusion Criteria}

Gestational age >10 weeks, Ectopic pregnancy, Molar pregnancy, Uterine anomalies, Pelvic infection, Bleeding disorders.

The women fulfilling the inclusion criteria are subjected randomly to either MVA or EVA. In all selected cases, a detailed history is taken. Bimanual pelvic examination is done to know the position, size \& mobility of uterus, the presence of infection, any forniceal tenderness (PID) \& ectopic pregnancy. The basic investigations (Hemoglobin percentage, Blood grouping and Rh-typing, Urine examination for microscopy, albumin \& sugar and, if required, Ultrasonography) were done.

After explaining the procedure to the patient, an informed written consent was taken. The women were counselled about pain, vaginal bleeding, and possibility of complications. The patients were then subjected to either MVA or EVA.

In all 200 cases, the time taken for the procedure, total blood loss, post-operative pain \& bleeding, other complications, \& duration of hospital stay are studied. Time taken for the procedure was measured in minutes, from the insertion of cannula into the uterus to the end of procedure.

Blood loss was calculated by subtracting fifty $\mathrm{ml}$ from volume of conceptus in the MVA syringe \& the suction jar in MVA \& EVA respectively.

In both groups, the pain appreciated by the patient was graded as:

Grade 1: Nil; Woman is comfortable. No facial expressions of pain.

Not complaining of cramping in lower abdomen.

Grade 2: Minimal; Woman complaining of mild cramping lower abdominal pain.

No facial expressions of pain.

Grade 3: Moderate. No analgesics needed. Woman complaining of moderate cramping lower abdominal pain which is tolerable.

Facial expressions of pain noted.

Grade 4: Severe. Needing analgesics; Woman complaining of severe lower abdominal pain.

Facial expressions indicating severe pain.

May or may not be associated with nausea, vomiting.

In the post-operative period, the amount of bleeding was assessed by checking the soakage of the diapers and bleeding was graded as:

Grade 1: Less than normal i.e., spotting only or no bleeding.

Grade 2: Normal i.e., soakage of one pad.

Grade 3: More than normal i.e., soakage of 2 or more pads.

Depending on the severity of pain, amount of bleeding \& any other complications, patient was discharged with appropriate contraceptive method. $\mathrm{t}$-value, $\mathrm{p}$-value and $\mathrm{x}^{2}$ -value were used for statistical analysis. 


\section{RESULTS}

Among the 200 women enrolled in the study, 100 women had undergone MVA and EVA each. Age of the women and gravidity were similar in both groups (Table 1). In both procedures, maximum number of cases were between 8-10weeks gestation, which is statistically highly significant $(\mathrm{p}>0.001)$.

$37 \%$ patients in MVA had grade I pain and 54\% patients in EVA had grade IV pain, which is highly significant (Table 2). $72 \%$ cases in MVA had grade I bleeding \& $48 \%$ in EVA had grade II bleeding. The bleeding after MVA procedure was less as compared to EVA, which is highly significant $(\mathrm{p}<0.001)$. The common complications noted were incomplete abortion (1\% in MVA \& 4\% in EVA), and cervical laceration (none in MVA and $3 \%$ in EVA). Cervical laceration was common in EVA during insertion of rigid metallic cannula which was not encountered in MVA due to use of soft flexible plastic non-metallic cannulae. Uterine perforation did not occur in any case undergoing either MVA or EVA.

In MVA, mean average time taken is less by 5-6 minutes and average blood loss is also less by $8 \mathrm{ml}$ as compared to EVA, is which is highly significant $(p<0.001)$. Women were discharged in 6-8 hours and 12-16 hours in MVA \& EVA respectively (Table 3).

Table 1: Base line characteristics.

\begin{tabular}{|c|c|c|c|c|}
\hline Parameters & & MVA $(n=100)$ & EVA $(n=100)$ & p-value \\
\hline \multirow{3}{*}{ Age } & $\leq 20 \mathrm{Yrs}$ & 10 & 15 & \multirow{3}{*}{$\mathrm{p}>0.05, \mathrm{NS}$} \\
\hline & 21-30 Yrs & 71 & 64 & \\
\hline & $>31 \mathrm{Yrs}$ & 19 & 21 & \\
\hline \multirow{3}{*}{ Gravidity } & Primigravida & 11 & 13 & \multirow{3}{*}{$\mathrm{p}>0.05, \mathrm{NS}$} \\
\hline & $\begin{array}{l}\text { Gravida-II to } \\
\text { Gravida-IV }\end{array}$ & 69 & 64 & \\
\hline & $>$ Gravida-IV & 20 & 23 & \\
\hline \multirow{2}{*}{ Period of gestation } & 5-7 weeks & 36 & 18 & \multirow{2}{*}{$\mathrm{p}<0.001, \mathrm{HS}$} \\
\hline & 8-10weeks & 64 & 82 & \\
\hline
\end{tabular}

Table 2: Comparison of grades of pain, grades of bleeding \& complications.

\begin{tabular}{|c|c|c|c|c|}
\hline Parameters & MVA $(n=100)$ & EVA $(n=100)$ & $\mathrm{x}^{2}$-value & p-value \\
\hline \multicolumn{5}{|l|}{ Grades of pain } \\
\hline Grade-I & 37 & 00 & \multirow{4}{*}{78.37} & \multirow{4}{*}{$\mathrm{p}<0.001$} \\
\hline Grade-II & 27 & 13 & & \\
\hline Grade-III & 29 & 33 & & \\
\hline Grade-IV & 07 & 54 & & \\
\hline \multicolumn{5}{|l|}{ Grades of bleeding } \\
\hline Grade-I & 72 & 13 & \multirow{3}{*}{77.44} & \multirow{3}{*}{$\mathrm{p}<0.001$} \\
\hline Grade-II & 24 & 48 & & \\
\hline Grade-III & 04 & 39 & & \\
\hline No. of complications & 07 & 19 & & $\mathrm{p}<0.001$ \\
\hline
\end{tabular}

Table 3: Comparison of procedure time, blood loss \& duration of hospital stay.

\begin{tabular}{|lllll|}
\hline \multirow{2}{*}{ Parameters } & MVA $(\mathbf{n}=\mathbf{1 0 0})$ & EVA $(\mathbf{n}=\mathbf{1 0 0})$ & t-value & p-value \\
\cline { 2 - 5 } & Mean \pm SD & Mean \pm SD & 21.13 & $\mathrm{P}<0.001$ \\
\hline Procedure time(in minutes) & $6.17 \pm 1.69$ min & $11.45 \pm 1.84$ & 9.49 & $\mathrm{P}<0.001$ \\
\hline Blood loss (ml) & $28.45 \pm 5.56$ & $36.68 \pm 6.66$ & 2.05 & $\mathrm{P}<0.001$ \\
\hline Duration of hospital stay (hours) & $7.43 \pm 6.59$ & $15.06 \pm 13.51$ & \\
\hline
\end{tabular}


In 16 cases of associated medical conditions in the MVA group, 7 cases were associated with hypertension and 6 cases with rheumatic heart disease, as compared to 3 and 1 in EVA group respectively. So, MVA was used safely in medical conditions associated with MTP procedure.

Of the 7 cases of associated surgical conditions in MVA group, 5 had ovarian cysts and 2 had past history of appendicectomy. Similarly, of the 5 cases of associated surgical conditions in EVA, 3 had associated ovarian cyst and 2 had undergone appendicectomy in the past. So, MVA was used safely as compared to EVA in surgical conditions associated with MTP.

\section{DISCUSSION}

Simplified and safe methods of first trimester abortion have been under trial since 1970s. The simplicity of vaccum aspiration under local anesthesia, with or without sedation, introduced out patient management in place of inpatient one.

Alison Edelman et $\mathrm{al}^{3}$ and Mohamed Abd El Ghafar ${ }^{10}$ studies show that the time consumed for EVA procedure was shorter than MVA group. In the present study, there was a significantly less time consumed for MVA procedure as compared to EVA procedure which was comparable with Das Vinita et $\mathrm{al}^{1}$, P. D. Blumenthal et $\mathrm{al}^{7}$, Goldberg A B et $\mathrm{al}^{5}$ and Kamel Helen (2012) et al ${ }^{11}$ study. This difference of time consumption could be attributed to type of anaesthesia used, skills of the clinician and also on the period of gestation. In our study, most of the MVA cases were performed under paracervical block and most of the EVA cases were performed either under short general anaesthesia or under spinal anaesthesia. So, in our study, MVA helped save the time of both the patient $\&$ the clinician. Blood loss was $35.4 \pm 16.8 \mathrm{ml}$ in Goldberg AB (2004) et $\mathrm{al}^{5}$ study, similar to present study of $28.45 \pm 5.56 \mathrm{ml}$ in MVA. Crenin MD $^{6}$ study showed average duration of hospital stay as 5.8 hours in MVA and 19.3 hours in EVA, which was comparable with present study where hospital stay duration was $7.43 \pm 6.59$ hours in MVA and $15.06 \pm 13.51$ hours in EVA group. P.D. Blumenthal et $\mathrm{al}^{7}$ interpreted that, the waiting time for MVA procedure was reduced by $52 \%$ and the total hospital costs reduced by $41 \%$.

MVA group appreciated less pain and required less analgesia in comparison with EVA group, which was similar to Gomez et al ${ }^{[8]}$ study who found significant differences when comparing level of pre-operative and intraoperative pain $(\mathrm{p}<0.001)$. Das Vinita et $\mathrm{al}^{2}$ and Goldberg et $\mathrm{al}^{5}$ had relatively more complications in MVA group as $9 \%$ and $2 \%$ as compared to $6 \%$ and $2 \%$ in EVA group respectively. This difference can be attributed to the skills of the clinician and the period of gestation not corresponding to LMP. Uterine perforation was not noted in either MVA or EVA groups in our study as similar to Kamel Helen et al ${ }^{11}$ study. This indicates the safety of both procedures for first trimester abortion.

Crenin et $\mathrm{al}^{6}$ found success rate of $98 \%$ with MVA which was similar to present study with success rate of $99 \%$ in MVA and $90 \%$ with EVA. Das Vinita et al ${ }^{1}$ had $96.1 \%$ and $98 \%$ success rates with MVA and EVA respectively. This difference may be due to cases whose period of gestation was not corresponding to menstrual age and so lead to retained products and re-aspiration.

MVA is as safe as EVA for abortions upto 10 weeks gestation. ${ }^{5,9}$ Expanded use in an office setting might increase abortion access. ${ }^{5}$

\section{CONCLUSION}

Every woman has the right to take decision about conceiving and continuing her pregnancy or terminating it. So, the early detection and termination of unwanted pregnancy by safe means is the aim of all clinicians. WHO warrants that services for voluntary termination of pregnancy should be an integral part of maternity and family health services.

MVA has many advantages with respect to equipment, no need for electricity, flexible plastic cannulae, easy method of disinfection, easy portability, less complication rates, and an office procedure, it is best suited for rural setting, where there is unmet need for abortion services. So, MVA has become safer and more feasible in low resource settings. MVA can be preferred for first trimester abortions upto ten weeks gestation.

Funding: No funding sources

Competing interests: There are no competing interests to declare

Ethical approval: The study was approved by the institutional ethical committee

\section{REFERENCES}

1. Das V, Jain S, Gupta HP, Agarwal A, Sujatha, Pandey A. Evaluation of newer methods of early pregnancy termination. J Obstet Gynecol India 2005;55:454-6.

2. Sharma M. Sublingual misoprostol for cervical priming in surgical first trimester pregnancy termination. J Obstet Gynecol India 2011;61:531-3.

3. Edelman A, Nichols MD, Jenson J. Comparison of pain and time of procedures with two first trimester abortion techniques preformed by residents and faculty. Am J Obstet Gynecol 2001;184;1564-7.

4. Issac LM, Darney P. Early surgical abortion: An alternative to and back up for medical abortion. Am J Obstet Gynecol 2000;183:S76-S83.

5. Goldberg AB, Dean G, Kang MS, Youssof S, Damey PD. Manual Vs Electric Vaccum aspiration for early first trimester abortion: A controlled study 
of complication rates. Obstet Gynecol 2004;103:101-7.

6. Edward J, Crenin MD. Surgical abortion for gestation of less than 6 weeks. Curr Probl Obstet Gynecol Fertil 1997;20:11-9.

7. Blumenthal PD, Remsburg RE. A time and cost analysis of the management of incomplete abortion with manual vaccum aspiration. Int J Gynec Obstet 1991;451:261-7.

8. Gómez PI, Gaitán H, Nova C, Paradas A. Paracervical block in incomplete abortion using manual vacuum aspiration: randomized clinical trial. Obstet Gynecol 2004;103(5 Pt 1):943-51.
9. Dean G, L Cardenas, Damey P, Gold Berg A. Acceptability of Manual Vs electric aspiration for first trimester abortion: A randomized trial. Contraception 2003;67:201-6.

10. Mohamed Abd El Ghafar. Comparative study of dilatation and curettage, Manual and Electric vaccum aspiration as methods of treatment of early abortion in Bei Suef, Egypt. Int Res J Med Medical Sciences 2013;1:43-50.

11. Kamel H, Goswami S, Dutta R. Manual vacuum aspiration and Electric vacuum aspiration - A comparative study for first trimester MTP. J Obstet Gynaecol India 2012;61:53-6.

DOI: $10.5455 / 2320-1770 . i j r c o g 20130618$

Cite this article as: Kerure SB, Kerure RD, Sagarad SS, Biradar V. A comparative study of manual vaccum aspiration (MVA) \& electric vaccum aspiration (EVA) for pregnancy termination of upto 10 weeks gestation. Int $\mathbf{J}$ Reprod Contracept Obstet Gynecol 2013;2:199203. 